\title{
Artificial light pollution increases nocturnal vigilance in peahens
}

Jessica Yorzinski, Sarah Chisholm, Sydney Byerley, Jeanee Coy, Aisyah Aziz, Jamie Wolf, Amanda C Gnerlich

Artificial light pollution is drastically changing the sensory environments of animals. Even though many animals are now living in these changed environments, the effect light pollution has on animal behavior is poorly understood. We investigated the effect of light pollution on nocturnal vigilance in peahens (Pavo cristatus). Captive peahens were exposed to either artificial lighting or natural lighting at night. We employed a novel method to record their vigilance behavior by attaching accelerometers to their heads and continuously monitoring their large head movements. We found that light pollution significantly increases nocturnal vigilance in peahens. Furthermore, the birds faced a trade-off between vigilance and sleep at night: peahens that were more vigilant spent less time sleeping. Given the choice, peahens preferred to roost away from high levels of artificial lighting but showed no preference for roosting without artificial lighting or with low levels of artificial lighting. Our study demonstrates that light pollution can have a substantial impact on animal behavior that can potentially result in fitness consequences. 


\section{1}

2

3

5 Jessica L. Yorzinski ${ }^{1,2^{*}}$, Sarah Chisholm ${ }^{3}$, Sydney D Byerley ${ }^{2}$, Jeanee R. Coy ${ }^{2}$, Aisyah Aziz ${ }^{2}$,

$7 \quad{ }^{1}$ Department of Biological Sciences, Purdue University, 915 West State Street, West Lafayette

$9 \quad{ }^{2}$ Department of Animal Sciences, Purdue University, 915 West State Street, West Lafayette, IN

$11{ }^{3}$ Centre of Computational Statistics and Machine Learning, University College London, WC1E

12

13

14

15

16

17

18

19

20

21

22

23

24
6BT UK 


\section{ABSTRACT}

26 Artificial light pollution is drastically changing the sensory environments of animals. Even

27 though many animals are now living in these changed environments, the effect light pollution

28 has on animal behavior is poorly understood. We investigated the effect of light pollution on nocturnal vigilance in peahens (Pavo cristatus). Captive peahens were exposed to either artificial

30 lighting or natural lighting at night. We employed a novel method to record their vigilance

31 behavior by attaching accelerometers to their heads and continuously monitoring their large head

32 movements. We found that light pollution significantly increases nocturnal vigilance in peahens.

33 Furthermore, the birds faced a trade-off between vigilance and sleep at night: peahens that were

34 more vigilant spent less time sleeping. Given the choice, peahens preferred to roost away from

35 high levels of artificial lighting but showed no preference for roosting without artificial lighting or with low levels of artificial lighting. Our study demonstrates that light pollution can have a

37 substantial impact on animal behavior that can potentially result in fitness consequences. 
48 Humans are rapidly altering natural environments and this can lead to dramatic changes in the

49 sensory landscape. One change to the sensory landscape that has particularly pronounced effects

50 on wildlife is artificial light (Longcore and Rich 2004; Tuomainen, and Candolin 2011; Sol et al.

51 2013; Gaston et al. 2014). Artificial light is created by many different sources, such as

52 streetlights, lighted buildings or towers, and security lights. Nearly $20 \%$ of land on earth is

53 considered polluted by light (Cinzano et al. 2001) and this pollution is increasing every year

54 (Hölker et al. 2010). Light pollution has immediate fitness impacts on animals (Rich and

55 Longcore 2006). Animals that fail to adjust their behavior in response to artificial light can have

56 reduced survival and reproductive success. In extreme cases, species may even become at risk of

57 extinction (Stockwell 2003).

58 Animals exhibit altered behavior in response to light pollution. Increased nocturnal

59 illumination affects movement patterns. Rather than moving toward the sea, hatchling turtles are

60 attracted to shoreline lights and fail to begin their oceanic migrations (Tuxbury and Salmon

61 2005). The movement patterns of migrating birds are also disrupted. They are attracted to

62 artificial lights on overcast nights and remain near those lights rather than continuing their

63 migration (Avery et al. 1976). Artificial light can impact courtship behavior. Songbirds initiate

64 singing earlier in the morning and can even obtain more extra-pair mates when exposed to

65 environments with artificial lighting (Miller 2006; Kempenaers et al. 2010). In addition, light

66 pollution can alter predator-prey interactions. Harbor seals are more successful at capturing

67 salmonids in the presence of artificial light (Yurk and Trites 2000). Birds and bats can likewise

68 prey on moths at high rates when the moths congregate at artificial light sources (reviewed in

69 Frank 1988). Despite our growing knowledge on the effects of artificial light on animal behavior

70 (Rich and Longcore 2006; Gaston et al. 2014), we still know little about the mechanisms by 
71 which animals adjust their behavior in response to artificial nocturnal illumination (Tuomainen

72 and Candolin 2011; Kurvers and Holker 2015).

73 In contrast, we do know that variation in natural lighting at night influences vigilance

74 (Beauchamp 2007). Depending on moon phase, light at night can vary between about 0.5 lux for

75 a new moon and 2 lux for a full moon (Weaver 2011). This variation alters vigilance levels

76 differently depending on the species (Beauchamp 2015). Greater flamingos and tammar

77 wallabies increase their vigilance behavior at night when light levels are low (Beauchamp and

78 McNeil 2003; Biebouw and Blumstein 2003) but gerbils decrease their vigilance behavior in

79 response to low light levels (Kotler et al. 2010). Because nocturnal light levels can vary based on

80 sleeping sites (Gorenzel and Salmon 1995; Longcore and Rich 2007), animals can choose to

81 sleep under preferred lighting conditions (Nersesian et al. 2012). Their choice of sleeping sites

82 and vigilance behavior will in turn affect their sleep (Gauthier-Clerc et al. 2000). However, we

83 do not know how prey species alter their nocturnal vigilance behavior when exposed to artificial

84 lighting.

85 We therefore investigated the effects of light pollution on nocturnal vigilance behavior in

86 peafowl. Peafowl are an appropriate species in which to examine this topic because they must

87 increasingly live in well-lit urban environments due to habitat loss (Ramesh and McGowan

88 2009). They are a lekking species that are native to the Indian subcontinent but have also been

89 introduced to North America and other regions (Kannan and James 1998). At night, they roost on

90 tall structures (such as trees and poles; de Silva et al. 1996; Parasharya, 1999) and periodically

91 open their eyes to scan their environment (Yorzinski and Platt 2012). Many nocturnal predators,

92 such as tigers, jackals, and raccoons, could potentially prey on them (Harihar et al. 2007; de

93 Silva et al. 1996; Kannan and James 1998). 
We developed a novel method for monitoring vigilance rates by using accelerometers.

95 Accelerometers have become an increasingly popular tool for studying animal behavior (e.g.,

96 Sakamoto et al. 2009; Grünewälder et al. 2012; Nathan et al. 2012). They are often attached to an

97 animal's back and can be used to classify general activity patterns (e.g., flying, resting, walking;

98 Sakamoto et al. 2009). Accelerometers that are attached to animals' heads can record head

99 movements (Kokubun et al. 2011). Since high head movement rates are related to heightened

100 antipredator vigilance (e.g., Jones et al. 2007), we can use head movement rates to approximate

101 vigilance levels.

102

103 METHODS

104 We examined the effect of artificial light pollution on vigilance levels in a captive population of 105 adult peahens. The artificial light experiment was conducted between October 2013 and July

1062014 at the Purdue Wildlife Area in West Lafayette, IN, USA $\left(40.450327^{\circ} \mathrm{N},-87.052574^{\circ} \mathrm{E}\right)$.

107 The peafowl were housed in a large outdoor aviary $(24.4 \times 18.3 \times 1.8 \mathrm{~m})$ in an open area and

108 were given food and water ad libitum. The study was approved by Duke University Animal Care

109 and Use Committee (A205) and Purdue University Animal Care and Use Committee

110 (\#1305000862 \& 1504001232).

111

112 Artificial light experimental procedure

113 We conducted thirteen light trials and thirteen control trials to test the effect of artificial light on

114 vigilance behavior. A given bird was tested in either a light trial or a control trial (the order was

115 randomized across birds; 26 different birds were therefore tested overall). For each trial, a

116 female was transported to an experimental cage $(9 \mathrm{~m} \mathrm{x} 4.5 \mathrm{~m})$. The experimental cage was a 
117 section within the main aviary that was surrounded by black plastic. The black plastic went from

118 the ground to the roof on the two sides of the cage that faced the main aviary (this ensured that

119 the trial bird was unable to see the birds in the flock) and from the ground to $1.15 \mathrm{~m}$ tall on the

120 other two sides. It had a wooden sawhorse roost ( $0.85 \mathrm{~m}$ tall and $1.3 \mathrm{~m}$ long) that was positioned

$1214.5 \mathrm{~m}$ from an LED flood light (Philips 17-Watt Outdoor and Security Bright White; model:

122 PAR38; flicker rate: $38 \mathrm{kHz}$; spectral radiance has two peaks: $4 \mathrm{~mW} / \mathrm{nm}$ at $450 \mathrm{~nm}$ and 8.4

$123 \mathrm{~mW} / \mathrm{nm}$ at $600 \mathrm{~nm}$ (see Philips technical application guides for complete graph of spectral

124 radiance)), which was suspended from the roof (1.8 $\mathrm{m}$ from the ground). Before the female was

125 released into the experimental cage, a velcro strip $(3.5 \mathrm{~mm} \times 1.8 \mathrm{~mm})$ with elastic straps was

126 glued (Artiglio Super 620) to the feathers atop her head. After at least $1 \mathrm{hr}$, a 3-axis

127 accelerometer (TechnoSmart, Rome, Italy; $3 \mathrm{~mm}$ x $1.1 \mathrm{~mm} ; 0.5 \mathrm{~g}$; sample resolution: $19.6 \mathrm{~m} \mathrm{~s}^{-2}$;

128 sample rate: $50 \mathrm{~Hz}$ ), which was protected in shrink wrap and electrical tape, was attached to the

129 bird's head using velcro and secured by the strap (Figure 1). The bird was then released into the 130 experimental cage.

131 Each trial lasted seven nights. During a light trial, the light was off during nights 1, 6, and

1327 and was on during nights 2-5 (this experimental design is similar to the one used in Stone et al.

133 2009). When the light was initially turned on during the daytime of the second trial day, it

134 remained on (even during daylight) until the daytime after the fifth trial night. At night when the

135 light was turned on, the light intensity was 1260 lux below the light (light meter on ground

136 facing up at light) and 0.75 lux at the roost (light meter facing toward the light); when the light

137 was turned off, the light intensity was 0.04 lux below the light and 0.01 lux at the roost (Extech

138 EasyView 31 light meter; resolution: 0.01 lux for readings below 20 lux and 1 lux for readings

139 above 999; measurements taken during a night with clear skies and $69.5 \%$ moon illumination). 
140 During a control trial, the light was never turned on. An experimenter replaced the accelerometer

141 each day of a light and control trial (the accelerometer battery did not last more than $48 \mathrm{hr}$ ) and

142 did so at least $1 \mathrm{hr}$ after sunrise and $1 \mathrm{hr}$ before sunset. On the last day of each trial, the bird was

143 weighed (ZIEIS Veterinary Pet Scale; $5 \mathrm{~g}$ accuracy) and returned to the main aviary. The length

144 of the birds' tarsus + metatarsus was measured at the end of the entire experiment (Neiko digital

145 caliper, Neiko Tools, Wenzhou, Zhejiang, China; model number: 01409 A; $\pm 0.03 \mathrm{~mm}$ accuracy).

146 Three infrared camcorders (Night Owl CAM-600) connected to a DVR (Night Owl Apollo-45 or

147 LTE-44500) continuously recorded the area within the experimental cage and immediately

148 outside (2.5 $\mathrm{m}$ from the cage perimeter) the experimental cage.

149 We determined the number of head movements the birds made (see algorithm below)

150 during each night of the trials (starting $1 \mathrm{hr}$ after sunset and ending $1 \mathrm{hr}$ before sunrise;

151 "nighttime period"). Using the video recordings, we also calculated the percentage of time that

152 birds spent on the roost during the nighttime periods, the percentage of time that potential

153 predators and non-predators were visible along the perimeter of the experimental cage, when the

154 birds ascended to the roost for the night, and when the birds descended from the roost in the

155 morning. The time at which a bird ascended to the roost for the night was determined by moving

156 backwards in the videos from the nighttime period ( $1 \mathrm{hr}$ after sunset) and finding the time when

157 the bird jumped on the roost. If the bird was not already on the roost $1 \mathrm{hr}$ after sunset, then we

158 moved forward in the videos until the bird jumped on the roost. The time at which a bird

159 descended from the roost for the night was determined in a similar manner except that we moved

160 forward in the videos from the nighttime period ( $1 \mathrm{hr}$ before sunrise) until finding the time when

161 the bird jumped off the roost. If the bird was already off the roost $1 \mathrm{hr}$ before sunrise, we moved

162 backward in the videos until the bird jumped off the roost. We excluded times when the 
163 experimenters interfered with when the bird ascended to the roost or descended from the roost

164 (e.g., if the bird descended from the roost because the experimenter entered the enclosure).

165

166 Head movement extraction

167 In order to classify head movements using an accelerometer, we needed to examine the

168 accelerometer data with respect to the birds' behavior. Using similar steps as described above,

169 we performed 10 trials in which we video recorded the birds' behavior (Sony SR47) while they

170 were wearing an accelerometer at night (no artificial light was turned on). These trials were

171 performed from April through August 2013 in Durham, NC, USA $\left(36.01^{\circ} \mathrm{N}, 79.02^{\circ} \mathrm{W}\right)$ using the

172 same captive population as above (the birds were relocated from North Carolina to Indiana in

173 August 2013).

174 We synchronized the accelerometer data with the behavioral videos (Logger Pro, Vernier

175 Software and Technology, LLC; Figure 2; Video S1). We labeled the accelerometer data to

176 indicate when a head movement began and ended. We labeled small head movements (less than

$1775 \mathrm{deg}$ ) and large head movements (greater than $5 \mathrm{deg}$ ). The small head movements primarily

178 occurred when the bird blinked or moved its head slightly while sleeping; it is unlikely that these

179 small head movements were related to vigilance behavior and it was necessary to exclude them

180 from the analysis. In order to quantitatively distinguish between small and large head

181 movements, we determined the absolute value of the range of the acceleration in the $\mathrm{x}, \mathrm{y}$, and $\mathrm{z}$

182 and then summed these three ranges ('acceleration range') for each head movement. We found

183 that $70 \%$ of the small head movements had an acceleration range below $4.61 \mathrm{~m} \mathrm{~s}^{-2}$ and $70 \%$ of

184 large head movements had an acceleration range above $5.30 \mathrm{~m} \mathrm{~s}^{-2}$. We therefore reclassified the 
185 coded data such that only head movements with an acceleration range greater than $4.90 \mathrm{~m} \mathrm{~s}^{-2}$

186 were classified as head movements (Video S2).

187 We created a custom algorithm (Matlab R2014a; The Mathworks Inc., Natick, MA,

188 USA) to extract head movements from the accelerometer data and used the labeled

189 accelerometer data to examine its accuracy. This algorithm is similar to that used in another

190 study that extracted head movements from accelerometer data (Kokubun et al. 2011) because it

191 also relies on a threshold system. Our algorithm performed two steps to extract head movements.

192 First, it identified times at which the change in sway acceleration (delta y) exceeded $1.37 \mathrm{~m} \mathrm{~s}^{-2}$.

193 This threshold value was determined based on one randomly-selected bird from the labeled

194 dataset. We adjusted this threshold value until the number of predicted head movements most

195 closely matched the number of actual head movements. Second, the algorithm filtered these

196 times to ensure that the same head movement was not counted as multiple head movements.

197 Based on the labeled data, head movements were at least $0.5 \mathrm{~s}$ apart. Therefore, this filter

198 removed a head movement if it was within $0.5 \mathrm{~s}$ of another head movement.

199

200 Accelerometer effect

201 We conducted eight trials (with eight different peahens) to test the effect of the accelerometer on

202 the birds' vigilance behavior. These trials were performed in February and March 2013 with the

203 population in Durham, NC, USA. On one night, the bird had an accelerometer attached to its

204 head; on the other night, the bird did not have an accelerometer attached to its head (the order of

205 accelerometer attachment was randomized across trials). The artificial light was not turned on.

206 Two infrared camcorders (Night Owl CAM-600) connected to a DVR (Night Owl Apollo-45 or

207 LTE-44500) continuously recorded the bird. We randomly selected three 10-min periods from 
208 both nights of each trial (the times were matched in each night) and manually scored the number 209 of head movements in each period.

210

211 Sleep effect

212 We conducted eight trials (with eight different peahens) to examine the relationship between

213 head movement rate and sleep behavior. These trials were performed in March and April 2015

214 with the population in West Lafayette, Indiana, USA in the experimental cage from the artificial

215 light experiment. Each bird had an accelerometer attached to her head and was tested during one

216 night. The artificial light was not turned on. Two infrared camcorders (Bolide Technology Group

217 IR Bullet Camera) connected to a DVR (Swann DVR4-2600) continuously recorded each bird

218 such that the left and right eye of the bird was visible. We randomly choose two 30-minute

219 periods (occurring after the bird ascended to the roost for the night and before the bird descended

220 from the roost in the morning) from each trial. For the left and right eye separately, we scored the

221 times at which the eyes were closed (excluding blinks; using Inqscribe software). We scored the

222 left and right eye separately because peahens (Yorzinski and Platt 2012), like other birds

223 (Rattenborg et al. 2000), asymmetrically close their eyes during sleep. We then determined the

224 percentage of time that both eyes were simultaneously closed ('sleep behavior'); the percentage

225 of time that both eyes were simultaneously closed was strongly correlated with the percentage of

226 time that the right eye was closed $\left(\mathrm{F}_{1,14}=2168, \mathrm{p}<0.0001, \mathrm{R}^{2}=0.99\right)$ and the left eye was closed

$227 \quad\left(\mathrm{~F}_{1,14}=2683, \mathrm{p}<0.0001, \mathrm{R}^{2}=0.99\right)$.

228

229 Roost Selection 
230 We conducted eight trials (with eight different peahens) to examine whether peahens prefer to

231 roost under artificial night lighting ('direct light') or away from the lighting ('low light'). These

232 trials were performed in April and May 2015 with the population in West Lafayette, Indiana,

233 USA in an experimental cage $(4.5 \mathrm{~m} \times 9.0 \mathrm{~m})$ that was $75 \mathrm{~m}$ from the large aviary. There were

234 two wooden sawhorse roosts $(0.85 \mathrm{~m}$ tall and $1.3 \mathrm{~m} \mathrm{long})$ that were positioned on opposite sides

235 of the cage (1.1 $\mathrm{m}$ from the cage sides and $6.8 \mathrm{~m}$ from each other). An LED flood light (Philips

236 17-Watt Outdoor and Security Bright White; model: PAR38) was suspended from the roof

237 directly above each roost (1.8 $\mathrm{m}$ from the ground). One of the lights was turned on during each

238 trial (randomized across trials). At night when the light was turned on, the light intensity was 3.0

239 kLux directly below the light (light meter on roost facing up at light) and 0.22 lux at the roost on

240 the opposite side of the cage (light meter facing toward the light; Extech EasyView 31 light

241 meter; measurements taken during a night with clear skies and 78.0\% moon illumination). Two

242 infrared camcorders (Night Owl CAM-600) connected to a DVR (Swann DVR4-2600)

243 continuously recorded each roost. Based on the video recordings, we determined whether the

244 bird spent the night on the roost that was under 'direct light' or 'low light.'

245 We performed another roost choice experiment to assess whether peahens prefer to roost

246 without any artificial light ('no light') or to roost with low levels of artificial light ('low light').

247 We tested 16 different peahens in individual trials that each lasted two nights. The trials lasted

248 two nights so that we could determine whether peahens were consistent in their roosting

249 preferences. This experiment was conducted from May to July 2015 in the same cage that was

250 used for the roost choice experiment above. Black plastic divided the cage in half (lengthwise)

251 but a small opening $(0.75 \mathrm{~m})$ did not have black plastic so that the bird could move between the

252 two sides of the cage. The black plastic ensured that light from one side of the cage did not enter 
253 into the other side. There was a wooden sawhorse roost ( $0.85 \mathrm{~m}$ tall and $1.3 \mathrm{~m}$ long) on both

254 sides of the cage ( $2 \mathrm{~m}$ from the cage side). An LED flood light (Philips 17-Watt Outdoor and

255 Security Bright White; model: PAR38) was suspended from the roof and positioned $4.5 \mathrm{~m}$ from

256 each roost (1.8 $\mathrm{m}$ from the ground). One of the lights was turned on during each trial

257 (randomized across trials). At night when the light was turned on, the light intensity was 1260

258 lux below the light (light meter on ground facing up at light), 0.75 lux at the roost that was in the

259 same side of the cage (light meter facing toward the light), and 0.01 lux at the roost that was in

260 the opposite side of the cage; when the light was turned off, the light intensity was 0.01 lux

261 below the light and 0.01 lux at each roost (Extech EasyView 31 light meter; measurements taken

262 during a night with clear skies and $26.4 \%$ moon illumination). Two infrared camcorders (Night

263 Owl CAM-600) connected to a DVR (Swann DVR4-2600) continuously recorded each roost.

264 Based on the video recordings, we determined whether the bird spent the night on the roost that

265 was under 'no light' or 'low light.'

266

267 Data analysis

268 We tested whether nocturnal vigilance (measured using the number of head movements) varied

269 with respect to lighting. We ran a repeated-measures mixed linear model (PROC Mixed with a

270 variance components (VC) covariance structure) with head movement rate (natural log

271 transformed to meet underlying assumptions of normality) as the dependent variable. The head

272 movement rate was calculated by summing the number of head movements that occurred in the

273 nighttime period and then dividing that sum by the total time in that nighttime period for each

274 night of each trial. 
The independent variables were the trial type (light trial or control trial), trial night (the

276

277

278

279

280

281

282

283

284

285

286

287

288

289

290

291

292

293

294

295

296

297

specific night of the trial: 1-7), and their interaction as well as environmental variables (wind speed, precipitation, temperature, moon illumination, predator presence, and non-predator presence) and morphological measurements of the bird (mass and tarsus + metatarsus). The climate variables were obtained from a nearby weather station (http://iclimate.org; ACRE- West Lafayette) and moon illumination was the fraction of the moon's surface that was illuminated from the sun's rays (http://www.timeanddate.com; Lafayette, IN). The wind speed (natural log transformed to meet underlying assumptions of normality) and temperature were averaged across the nighttime period. Since there was no precipitation during $79 \%$ of trial nights, precipitation was categorized as being present or not. Predator and non-predator presence was whether predators or non-predators, respectively, were visible along the outside of the perimeter or not during the nighttime period (predators and non-predators were visible in only $34.5 \%$ of nights).

We performed a priori contrasts to test whether head movement rates during each of the seven trial nights differed between the light trials and control trials as well as whether head movement rates differed between night 2 (first night of light) and 5 (last night of light) of the light trials. We ran two repeated-measures mixed linear models to determine the variables influencing the time (relative to sunset and sunrise) at which the birds ascended to the roost and descended from the roost for the night. The independent variables were the trial type (light trial or control trial), trial night (the specific night of the trial: 1-7), and their interaction as well as environmental variables during the nighttime period (wind speed, precipitation, temperature, and moon illumination) and morphological measurements of the bird (mass and tarsus + metatarsus).

We also ran repeated-measures mixed linear models to evaluate whether head movement rate (natural log transformed) (1) differed depending on whether the bird was wearing an 
298 accelerometer or not and (2) was related to sleep behavior. We performed binomial tests (Proc

299 Freq) to assess peahens' roosting preferences (the peahens never switched to a different roost

300 during a given night). All analyses were performed in SAS (9.3; Cary, NC, USA) or Minitab

301 (15.1; Minitab Inc., State College, PA, USA). The data supporting this article are available in

302 Harvard Dataverse: http://dx.doi.org/10.7910/DVN/J3RF1P.

303

304 RESULTS

305 The extraction algorithm accurately predicted the head movements of peahens from the

306 accelerometer data (Figure 2). Across all the birds, there were 1699 head movements observed in

307 the labeled dataset and the algorithm predicted that there were 1678 head movements (overall

308 accuracy: $98.8 \%$ correct). Averaging within birds, the overall accuracy was $96.1 \%$ (SE: $1.5 \%$ ).

309 Of the 1678 head movements that the algorithm predicted, 1536 of those head movements were

310 true head movements (the predicted head movement fell within the time period of an observed

311 head movement; "true accuracy": $90.4 \%$ correct). Averaging within birds, the true accuracy was

$31287.4 \%$ (SE: $3.4 \%$ ). The accuracies were similar even when excluding the trial from the bird that

313 was used to create the threshold value (see Materials and Methods; overall accuracy: $98.8 \%$; true

314 accuracy: 90.6\%). The accelerometer did not have an effect on the number of head movements

315 peahens made $\left(\mathrm{F}_{1,7}=0.15, \mathrm{p}=0.71\right.$; Figure 3$)$. Peahens that had lower head movement rates spent

316 more time sleeping $\left(\mathrm{F}_{1,7}=31.05, \mathrm{p}=0.0008\right.$; Figure 4$)$.

317 Head movement rate was related to the trial type (light trial or control trial; $F_{1,22}=30.45$,

$318 \mathrm{p}<0.0001$ ), trial night (the specific night of the trial; $\mathrm{F}_{6,102}=7.21, \mathrm{p}<0.0001$ ), and their interaction

$319\left(\mathrm{~F}_{6,102}=4.67, \mathrm{p}=0.0003\right)$. Birds that weighed less had higher head movement rates than birds that

320 weighed more $\left(\mathrm{F}_{1,22}=13.11, \mathrm{p}=0.0015\right)$ but the tarsus + metatarsus length was unrelated to head 
321 movement rates $\left(\mathrm{F}_{1,22}=0.01, \mathrm{p}=0.92\right)$. The climate variables and moon illumination had no

322 impact on head movement rate (wind: $\mathrm{F}_{1,102}=2.97, \mathrm{p}=0.088$; precipitation: $\mathrm{F}_{1,19}=1.61, \mathrm{p}=0.22$,

323 temperature: $F_{1,102}=1.59, p=0.21$, moon illumination: $\left.F_{1,102}=0.40, p=0.53\right)$. Importantly, the head

324 movement rates were unrelated to predator and non-predator presence (predator presence:

$325 \mathrm{~F}_{1,13}=1.15, \mathrm{p}=0.30$, non-predator presence: $\left.\mathrm{F}_{1,15}=0.59, \mathrm{p}=0.46\right)$. This is not unexpected given that

326 predator and non-predator presence was rare and these predators and non-predators were outside

327 the cage (and therefore largely visually blocked by the black plastic which surrounded the cage)

328 and not directly under the artificial light. However, head movements in peahens are related to

329 antipredator behavior. By manually analyzing head movements from a previous experiment in

330 which peahens were exposed to a taxidermy raccoon at night (without any artificial light

331 pollution; Yorzinski and Platt 2012), peahens made more head movements during a 1-min period

332 while the predator was moving toward them and then stopped in front of them (mean \pm SE: 6.21

$333 \pm 4.14$ ) compared to a 1-min period immediately before the predator was exposed (mean $\pm \mathrm{SE}$ :

$3340.80 \pm 0.91 ;$ paired $\mathrm{t}$-test: $\mathrm{n}=7 ; \mathrm{t}=3.77 ; \mathrm{p}=0.009$; we averaged the head movements from the two

335 peahens that were tested in each trial).

336 Artificial light pollution had a strong effect on head movement rates (Figure 5). The head

337 movement rate was similar on the first night of both trial types when no light was on $\left(\mathrm{t}_{1,102}=0.39\right.$,

$338 \mathrm{p}=0.69$ ). On the second, third, fourth, and fifth nights of the trials, when the light was on during

339 the light trials and off during the control trials, the head movement rate was higher in the light

340 trials compared to the control trials (second night: $\mathrm{t}_{1,102}=5.16, \mathrm{p}<0.0001$; third night: $\mathrm{t}_{1,102}=4.28$,

$341 \mathrm{p}=0.0002$; fourth night: $\mathrm{t}_{1,102}=3.52, \mathrm{p}=0.0006$; fifth night: $\mathrm{t}_{1,102}=2.13, \mathrm{p}=0.036$ ). On the sixth and

342 seventh nights, when the light was off in both trial types, there was no difference in head

343 movement rate (sixth night: $\mathrm{t}_{1,102}=0.25, \mathrm{p}=0.80$; seventh night: $\mathrm{t}_{1,102}=0.23, \mathrm{p}=0.82$ ). During light 
344 trials, the head movement rate was higher on the first night that the light was on (night 2)

345 compared to the last night that the light was on (night $5 ; \mathrm{t}_{1,102}=2.51, \mathrm{p}=0.014$ ). The results were

346 qualitatively the same if the head movement rate was not log transformed except there was no

347 significant difference between head movement rates during night five in both the light and

348 control trials $\left(\mathrm{t}_{1,102}=1.68, \mathrm{p}=0.096\right)$. If the $\mathrm{p}$-values are corrected for multiple comparisons using

349 the Holm-Bonferroni method, there is no significant difference between head movement rates

350 during night five in both the light and control trials nor between the first night that the light was

351 on compared to the last night that the light was on in the light trials.

352 Peahens remained on the roost for most (97.2\%) of the total nighttime period (the

353 nighttime periods from all the trial nights across both treatments). They roosted on the ground for

354 the entire nighttime period in only $2.3 \%$ of trial nights. During trials when they remained off the

355 roost for only a portion of the nighttime period (11 nights), they primarily did so during light

356 trials on nights when the light was on (10 nights). Potential predators (cats, raccoons, opossums,

357 and owls) spent little time ( $0.25 \%$ of the total nighttime period) directly outside the cage. The

358 percentage of time that predators were present outside the cage was unaffected by whether the

359 light was on or off (Kruskal-Wallis: $\mathrm{H}=0.06 ; \mathrm{p}=0.81$ ). Non-predators (frogs, mice, rabbits, and

360 skunks) spent slightly more time outside the cage ( $2.36 \%$ of the total nighttime period) than

361 predators and they spent more time outside the cage when the light was on compared to when it

362 was off (Kruskal-Wallis: $\mathrm{H}=7.52 ; \mathrm{p}=0.0061$ ). Peahens ascended to the roost later in the night

363 when the temperature was higher $\left(\mathrm{F}_{1,105}=4.45, \mathrm{p}=0.037\right)$; the other independent variables,

364 including the trial type, did not affect when the birds ascended to the roost $(\mathrm{p}>0.07)$. Peahens

365 descended from the roost later in the morning when the moon illumination was higher 
$366\left(\mathrm{~F}_{1,109}=10.12, \mathrm{p}=0.0019\right)$; the other independent variables, including the trial type, did not affect

367 when the birds descended from the roost $(\mathrm{p}>0.08)$.

368 Peahens exhibited a strong preference for roosting away from direct artificial lighting

369 ( $\mathrm{p}=0.0078$, two-tailed binomial test). In fact, all of the peahens $(\mathrm{n}=8)$ chose to roost in 'low

370 light" compared to 'direct light.' In contrast, peahens $(\mathrm{n}=16)$ did not show a preference for

371 roosting in 'no light' versus 'low light' conditions (night one: $\mathrm{p}=0.32$, two-tailed binomial test;

372 night two: $\mathrm{p}=0.62$, two-tailed binomial test). Most of the birds $(69 \%)$ roosted in the same

373 location during both nights of their trials. However, one bird roosted in the dark during the first

374 night and in the low light for the second night while four birds did the opposite.

375

376 DISCUSSION

377 Artificial light pollution increases nocturnal vigilance in peahens. Peahens exhibited a higher rate

378 of head movements (a proxy of vigilance; Jones et al. 2007) on nights when artificial light was

379 present compared to nights when artificial light was absent. These higher head movement rates

380 were not caused by actual threats in the environment-- predator presence was rare and unrelated

381 to the number of head movements that peahens made. Furthermore, peahens that exhibited

382 higher head movement rates spent less time sleeping.

383 Even though animals are increasingly confronted with artificial light pollution, we are

384 only beginning to understand the effects it has on their behavior. Artificial night lighting affects

385 general activity patterns. This is unsurprising given that light is an important factor in mediating

386 circadian rhythms (Fonken and Nelson 2014). Some birds extend the times during which they

387 forage when exposed to artificial light. Mockingbirds feed their nestlings late in the evening

388 when under high artificial light levels (Stracey et al. 2014). European blackbirds continue 
389 foraging longer into the evening (Russ et al. 2015) and begin their mornings earlier (Dominoni et

390 al. 2014) when exposed to artificial night lighting. Artificial lighting can therefore alter basic

391 activity patterns but the fitness consequences of these changes are unknown. Artificial lighting

392 can even affect physiological processes. Siberian hamsters have reduced immune function when

393 exposed to artificial lighting (Bedrosian et al. 2011) and the reproductive systems of birds

394 change under artificial lighting (Dominoni et al. 2013). During the rare occasions when peahens

395 descended from the roost during the night in this study, they primarily did so during nights when

396 the artificial light was on and they would begin foraging on the ground. Mice also alter their

397 feeding habits when exposed to increased nocturnal lighting and this can lead to excess weight

398 gain (Fonken et al. 2010). However, unlike some species (Dominoni et al. 2014), artificial

399 lighting did not influence the timing of when peahens ascended to the roost or descended from

400 the roost in the evening or morning, respectively. Because the peahens had unlimited access to

401 food in this captive study, it may have been unnecessary for them to take advantage of increased

402 lighting by maximizing their foraging time.

403 Artificial light pollution affects predator-prey relationships. Predators, including harbor

404 seals and bats, are more successful at capturing their prey when artificial light pollution is

405 present than absent (Rydell 1992; Yurk and Trites 2000; Minnaar et al. 2014). Avian and aquatic

406 predators may also be more successful at capturing prey under artificial night lighting (reviewed

407 in Frank 1988; Becker et al. 2013). In response to high predation rates under artificial light, prey

408 can alter their anti-predator strategies. Frogs decrease their calling rates when exposed to

409 artificial nocturnal light and this may reduce their predation risk (Baker and Richardson 2006).

410 This study demonstrates that peahens increase their vigilance rate in response to artificial night

411 lighting. 
413 (Caro 2005). Individuals that are more vigilant are faster at detecting predators (Lima and

414 Bednekoff 1999). Antipredator vigilance occurs when animals scan their environment for

415 potential predators (Bednekoff and Lima 2002). Head movements are one way in which animals

416 can remain vigilant because it allows them to rapidly shift their visual field (reviewed in Jones et

417 al. 2007). Such vigilance can be useful to detect both predators and monitor conspecifics (Lung

418 and Childress 2007). Individuals can also remain vigilant by moving their eyes (Yorzinski and

419 Platt 2014) and "peeking” (periodically opening their eyes while sleeping; Lendrem 1984).

420 Individuals in large groups are often less vigilant than those in small groups (Lima 1995).

421 Vigilance is also affected by where animals choose to sleep. Animals can select sleeping sites

422 with varying levels of vegetation and accessibility to reduce predation risk (Lazarus and

423 Symonds 1992). Some species may prefer roosting under artificial lighting because they can

424 detect predators more easily (Gorenzel and Salmon 1995). In contrast, other prey species may be

425 more vulnerable to predation by sleeping under artificial lighting (Longcore and Rich 2007). In

426 this study, peahens preferred to roost further away from high levels of artificial lighting

427 (although they showed no preference between roosting under low level artificial lighting and no

428 artificial lighting). However, when the peahens' only option was to sleep near artificial lighting,

429 they exhibited higher vigilance rates than they did when exposed to natural night lighting.

430 Therefore, they may be compensating for increased predation risk by increasing their vigilance

431 levels. Peahens may exhibit low vigilance rates under natural conditions at night (i.e., only

432 moonlight) because they see poorly in low-light environments (Yorzinski and Platt 2012). It

433 would be informative to present predators to the birds at night to assess their predator detection

434 abilities. Given their increased vigilance levels during nights with artificial light pollution, we 
435 would expect them to detect predators more quickly than during nights without artificial light 436 pollution.

We also found that vigilance behavior and sleep are inversely related. Peahens that were

438

439

440

441

442

443

444

445

446

447 448 factors, both natural and anthropogenic, that influence vigilance behavior. trade-off between vigilance behavior and sleep may explain why peahens showed decreased (Thomas et al. 2000) or other costs that outweigh the benefits of being more alert at night. It can be difficult to obtain accurate measurements of vigilance because animals are frequently engaging in vigilance behavior throughout the day and night. Previous studies period (e.g., Jones et al. 2007). We developed a novel technique to automatically quantify nocturnal head movements in diurnal animals because the animals are primarily still at night except for head movements (and the accelerometer will therefore not mistake other behaviors with head movements). It can be a useful tool for future comparative studies to examine the

more vigilant spent less time sleeping (see also Gauthier-Clerc et al. 2000). We defined sleep as when both eyes of the birds were closed. Measuring their sleep using an electroencephalogram would provide additional information about their sleep stages (Campbell and Tobler 1984). The vigilance behavior after continued exposure to artificial lighting (their vigilance rate was higher on the first night that the artificial light was present compared to the last night that the light was present). Peahens that maintain high nocturnal vigilance rates may suffer cognitive impairments generally measure vigilance by manually recording this behavior during a relatively short timevigilance by using an accelerometer. An accelerometer positioned on the head of an animal can track all of the animal's head movements. This technique is especially powerful for recording

\section{ACKNOWLEDGEMENTS}


458 We thank the Purdue Department of Forestry and Natural Resources, especially Brian Beheler,

459 Ryan Hensley, Matt Kraushar, Michael Loesch-Fries, and Burk Thompson, for allowing us to

460 house the birds on their property and providing logistical support. Kailey Chema, Connor

461 Egyhazi, Fred Hermann, and Diamond Jones helped run some of the trials. Carlo Catoni and

462 Marco Scialotti provided technical support for the accelerometers and John Melville assisted us

463 in using Logger Pro. Merijn DeBakker offered advice in analyzing the accelerometer data.

464 Michael Platt, Barny Dunning, and Esteban Fernández-Juricic provided logistical support.

465

\section{REFERENCES}

467 Avery M, Springer PF, Cassel JF. 1976. The effects of a tall tower on nocturnal bird migration468 A portable ceilometer study. Auk 93:281-291.

Baker BJ, Richardson JML. 2006. The effect of artificial light on male breeding-season behaviour in green frogs, Rana clamitans melanota. Can J Zool. 84:1528-1532.

Bedrosian TA, Fonken LK, Walton JC, Nelson RJ. 2011. Chronic exposure to dim light at night suppresses immune responses in Siberian hamsters. Biology Letters 7: 468-471.

473

474

475

476

477

478

479

480

Becker A, Whitfield AK, Cowley PD, Järnegren J, Næsje TF. 2013. Potential effects of artificial light associated with anthropogenic infrastructure on the abundance and foraging behaviour of estuary-associated fishes. J Appl Ecol. 50: 43-50.

Bednekoff PA, Lima SL. 2002. Why are scanning patterns so variable? An overlooked question in the study of anti-predator vigilance. J Avian Biol 33:143-149.

Beauchamp G. 2007. Exploring the role of vision in social foraging: What happens to group size, vigilance, spacing, aggression and habitat use in birds and mammals that forage at night? Biol Rev. 82: 511-525. 
481 Beauchamp G, McNeil R. 2003. Vigilance in greater flamingos foraging at night. Ethol 109: 511-520.

483 Beauchamp G. 2015. Animal Vigilance: Monitoring Predators and Competitors.

$484 \quad$ Academic Press, London.

485 Biebouw K, Blumstein DT. (2003). Tammar wallabies (Macropus eugenii) associate safety with higher levels of nocturnal illumination. Ethology, Ecology, and Evolution 15: $159-172$.

Campbell SS, Tobler I. (1984). Animal sleep: A review of sleep duration across phylogeny. Neuroscience \& Biobehavioral Reviews 8: 269-300.

Caro T. (2005). Antipredator Defenses in Birds and Mammals. University of Chicago Press, Chicago, USA.

492

493

Cinzano P, Falchi F, Elvidge CD. 2001. The first world atlas of the artificial night sky brightness. MNRAS. 328:689-707.

de Silva PK, Santiapillai C, Dissanayake S. 1996. Some aspects of the population ecology of the 495 blue peafowl, Pavo cristatus, in Ruhuna National Park, Sri Lanka. J South Asian Nat His 2:113-126.

Dominoni D, Quetting M, Partecke J. 2013 Artificial light at night advances avian reproductive physiology. Proc R Soc B 280: 20123017.

Dominoni DM, Carmona-Wagner EO, Hofmann M, Kranstauber B, Partecke J. 2014. Individual-based measurement of light intensity provide new insights into the effects of artificial light at night on daily rhythms of urban-dwelling songbirds. J Anim Ecol

503 Fonken LK, Workman JL, Walton JC, Weil ZM, Morris JS, Haim A, 
Nelson RJ. 2010. Light at night increases body mass by shifting the time of food intake. Proc Natl Acad Sci. 107:18664-18669.

506 Fonken LK, Nelson RJ. 2014. The effects of light at night on circadian clocks

$507 \quad$ and metabolism. Endocr Rev. 35:648-670.

508 Frank KD. 1988. Impact of outdoor lighting on moths: an assessment. J Lepid Soc. 42:63-93.

509 Gaston KJ, Duffy JP, Gaston S. 2014. Human alteration of natural light cycles: causes and $510 \quad$ ecological consequences. Oecologia, 176:917-931.

511 Gauthier-Clerc M, Tamisier A, Cézilly F. 2000. Sleep-vigilance trade-off in gadwall

$512 \quad$ during the winter period. Condor 102:307-313.

513 Gorenzel WP, Salmon TP. 1995. Characteristics of American crow urban roosts in $514 \quad$ California. J Wildlife Manage. 59:638-45.

515 Grünewälder S, Broekhuis F, Macdonald DW, Wilson AM, McNutt JW, Shawe-Taylor J, Hailes

516 S. 2012. Movement activity based on classification of animal behaviour with an 517 application to data from cheetah (Acinonyx jubatus). PLoS ONE. 7:e49120.

518 Harihar A, Kurien AJ, Pandav B, Goyal SP. 2007. Response of tiger population to habitat, wild 519 ungulate prey and human distances in Rajaji National Park, Uttarakhand, India. Final 520 Technical Report, Wildlife Institute of India, Dehradun.

521 Hart N. 2002. Vision in the peafowl (Aves: Pavo cristatus). J Exp Biol. 205:3925-3935.

522 Hölker F, Wolter C, Perkin EK, Tockner K. 2010. Light pollution as a biodiversity threat. Trends $523 \quad$ Ecol Evol 25:681-682.

524 Jones KA, Krebs JR, Whittingham MJ. 2007. Vigilance in the third dimension: head movement 525 not scan duration varies in response to different predator models. Anim Behav. 74:1181526 1187. 
527 Kannan R, James DA. 1998. Common peafowl (Pavo cristatus). In The Birds of North America $528 \quad$ (ed A. Polle and F. Gill), No. 377. Philadelphia.

529 Kempenaers B, Borgstrom P. Loes P, Schlicht E, Valcu M. 2010. Artificial night lighting affects

530 dawn song, extra-pair siring success, and lay date in songbirds. Curr. Biol. 20:1735-1739.

531 Kokubun N, Kim JH, Shin HC, Naito Y, Takahashi A. 2011. Penguin

532 head movement detected using small accelerometers: a proxy of prey encounter

$533 \quad$ rate. J Exp Biol. 214:3760-3767.

534 Kotler BP, Brown J, Mukherjee S, Berger-Tal O, Bouskila A. (2010). Moonlight

535 avoidance in gerbils reveals a sophisticated interplay among time allocation, vigilance

536 and state-dependent foraging. Proc R Soc Lond B 277: 1469-1474.

537 Kurvers RHJM, Holker F. (2015). Bright nights and social interactions: A neglected $538 \quad$ issue. Behavioral Ecology 26: 334-339

539 Lazarus J, Symonds M. 1992. Contrasting effects of protective and obstructive cover on

$540 \quad$ avian vigilance. Anim Behav. 43: 519-521.

541 Lendrem DW (1984) Sleeping and vigilance in birds, II. An experimental study of the

542 barbary dove (Streptopelia risoria). Anim Behav 32:243-248

543 Lima S. 1995. Back to the basics of anti-predatory vigilance: the group-size effect.

$544 \quad$ Anim Behav. 49:11-20.

545 Lima SL Bednekoff PA. 1999. Back to the basics of antipredator vigilance:

$546 \quad$ can nonvigilant animals detect attack? Anim Behav. 58:537-543.

547 Longcore T, Rich C. 2004. Ecological light pollution. Front Ecol Environ. 2:191-198.

548 Longcore T, Rich C. 2007. Lights out! For nature. Pp. 165-171 in C. Marín and J. 

Jafari (eds.), StarLight: a common heritage. StarLight Initiative La Palma Biosphere Reserve, Instituto De Astrofísica De Canarias, Government of The Canary Islands, Spanish Ministry of The Environment, UNESCO - MaB., Canary Islands, Spain.

552 553

Lung MA, Childress MJ. 2007. The influence of conspecifics and predation risk on the vigilance of elk (Cervus elaphus) in Yellowstone National Park. Behavioral Ecology 18: $12-20$.

Miller MW. 2006. Apparent effects of light pollution on singing behavior of American robins. Condor 108:130-139.

Minnaar C, Boyles JG, Minnaar IA, Sole CL, McKechnie AE. 2014. Stacking the odds: light pollution may shift the balance in an ancient predator-prey arms race. J Appl Ecol. doi: $10.1111 / 1365-2664.12381$.

Nathan R, Spiegel O, Fortmann-Roe S, Harel R, Wikelski M, Getz WM. 2012. Using tri-axial acceleration data to identify behavioral modes of free-ranging animals: general concepts and tools illustrated for griffon vultures. J Exp Biol 215:986-996.

Nersesian CL, Banks PB, McArthur C (2012). Behavioral responses to indirect and direct predator cues by a mammalian herbivore, the common brushtail possum. Behav Ecol Sociobiol 66: 47-55.

Parasharya BM. 1999. Roosting behavior of Indian peafowl Pavo cristatus. J Bomb Nat Hist Soc. 96:471-473.

Ramesh K, McGowan P. 2009. On the current status of Indian peafowl Pavo cristatus (Aves: Galliformes: Phasianidae): keeping the common species common. J Threat Taxa. 1:106108.

Rattenborg NC, Amlaner CJ, Lima SL. 2000. Behaviora, neurophysiological and 
572

573

574

575

576

577

578

579

580

581

582

583

584

585

586

587

588

589

590

591

592

593

594

evolutionary perspectives on unihemispheric sleep Neuroscience and Biobehavioral Reviews 24: 817-842.

Rich C, Longcore, T. 2006. Ecological Consequences of Artificial Night Lighting. Island Press, Washington, DC, USA.

Russ A, Rüger A, Klenke R. 2015. Seize the night: European blackbirds (Turdus merula) extend their foraging activity under artificial illumination. J Ornithol 156:123-131.

Rydell J. 1992. Exploitation of insects around streetlamps by bats in Sweden. Funct Ecol. 6:744750.

Sakamoto KQ, Sato K, Ishizuka M, Watanuki Y, Takahashi A, Daunt F, Wanless S. 2009. Can ethograms be automatically generated using body acceleration data from free-ranging birds? PLoS ONE 4:e5379.

Sol D, Lapiedra O, González-Lagos C. 2013. Behavioral adjustments for life in the city. Anim Behav. 85:1101-1112.

Stockwell CA. 2003. Contemporary evolution meets conservation biology. Trends Ecol Evol. 18:94-101.

Stone EL, Jones G, Harris S. 2009. Street lighting disturbs commuting bats. Curr Biol. 19:11231127.

Stracey CM, Wynn B, Robinson SK. 2014. Light pollution allows Northern mockingbird (Mimus polyglottos) to feed nestlings after dark. Wilson J Ornithol 126:366-369.

Thomas M, Sing H, Belenky G, Holcomb H, Mayberg H, Dannals R, Wagner JR. H, Thorne D, Popp K, Rowland L, Welsh A, Balwinski S, Redmond D. 2000. Neural basis of alertness and cognitive performance impairments during sleepiness. I. Effects of $24 \mathrm{~h}$ of sleep deprivation on waking human regional brain activity. J Sleep Res. 9:335-352 
595 Tuomainen U, Candolin U. 2011. Behavioral responses to human-induced environmental $596 \quad$ change. Biol Rev. 86:640-657.

597 Tuxbury SM, Salmon M. 2005. Competitive interactions between artificial lighting and natural 598 cues during seafinding by hatchling marine turtles. Biol Cons. 121:311-316.

599 Weaver RE. 2011. Effects of simulated moonlight on activity in the desert nightsnake $600 \quad$ (Hypsinglena chlorophaea). Northwest Science 85: 497-500.

601 Yorzinski JL, Platt ML. 2012. The difference between night and day: antipredator 602 behavior in birds. J Ethol. 30:211-218.

603 Yorzinski J.L., Platt, M.L. 2014. Selective attention in peacocks during predator 604 detection. Animal Cognition 17: 767-777.

605 Yurk H, Trites AW. 2000. Experimental attempts to reduce predation by harbor seals on out606 migrating juvenile salmonids. T Am Fish Soc. 129:1360-1366.

607

608

609

610

611

612

613

614

615

616

617 
622 Fig. 1. Peahen on the roost wearing an accelerometer.

623

624 Fig. 2. Sample of the accelerometer data in swing (X), sway (Y), and yaw (Z). Arrows indicate 625 the four times when the peahen makes a head movement. This graph is also displayed in the 626 supplemental video (Video S1).

627

628 Fig. 3. Head movement rate was similar regardless of whether the peahen was wearing an 629 accelerometer or not (means \pm SE).

630

631 Fig. 4. Peahens that exhibited lower head movement rates spent more time sleeping. Because 632 each peahen was sampled during two periods (see Methods), there are two circles per bird. 633

634 Fig. 5. Artificial light pollution increases head movement rates (means \pm SE). Head movement 635 rates were similar on nights when the artificial light was off in both light and control trials 636 (nights 1, 6, and 7). Head movement rates were significantly higher during nights when the 637 artificial light was on during the light trials and off during the control trials (nights 2-5).

638 Asterisks indicate significant differences in head movement rates between the light and control 639 trials. 
644 Video S1. Alert peahen on the roost at night wearing an accelerometer. The accelerometer data, 645 swing $(\mathrm{X})$, sway $(\mathrm{Y})$, and yaw $(\mathrm{Z})$, are synchronized with the video recording of the peahen. The 646 peahen made four head movements.

647

648 Video S2. Sleeping peahen on the roost at night wearing an accelerometer. The accelerometer 649 data, swing (X), sway (Y), and yaw (Z), are synchronized with the video recording of the 650 peahen. The peahen was initially asleep and making head movements that were too small to be 651 classified by the extraction algorithm as head movements (see "Head movement extraction" in 652 the Methods). She then awoke and made one head movement (14 s into the video) that was large 653 enough to be classified as a head movement by the extraction algorithm. 
1

Figure 1

PeerJ reviewing PDF | (2015:07:5712:1:2:NEW 18 Jul 2015) 


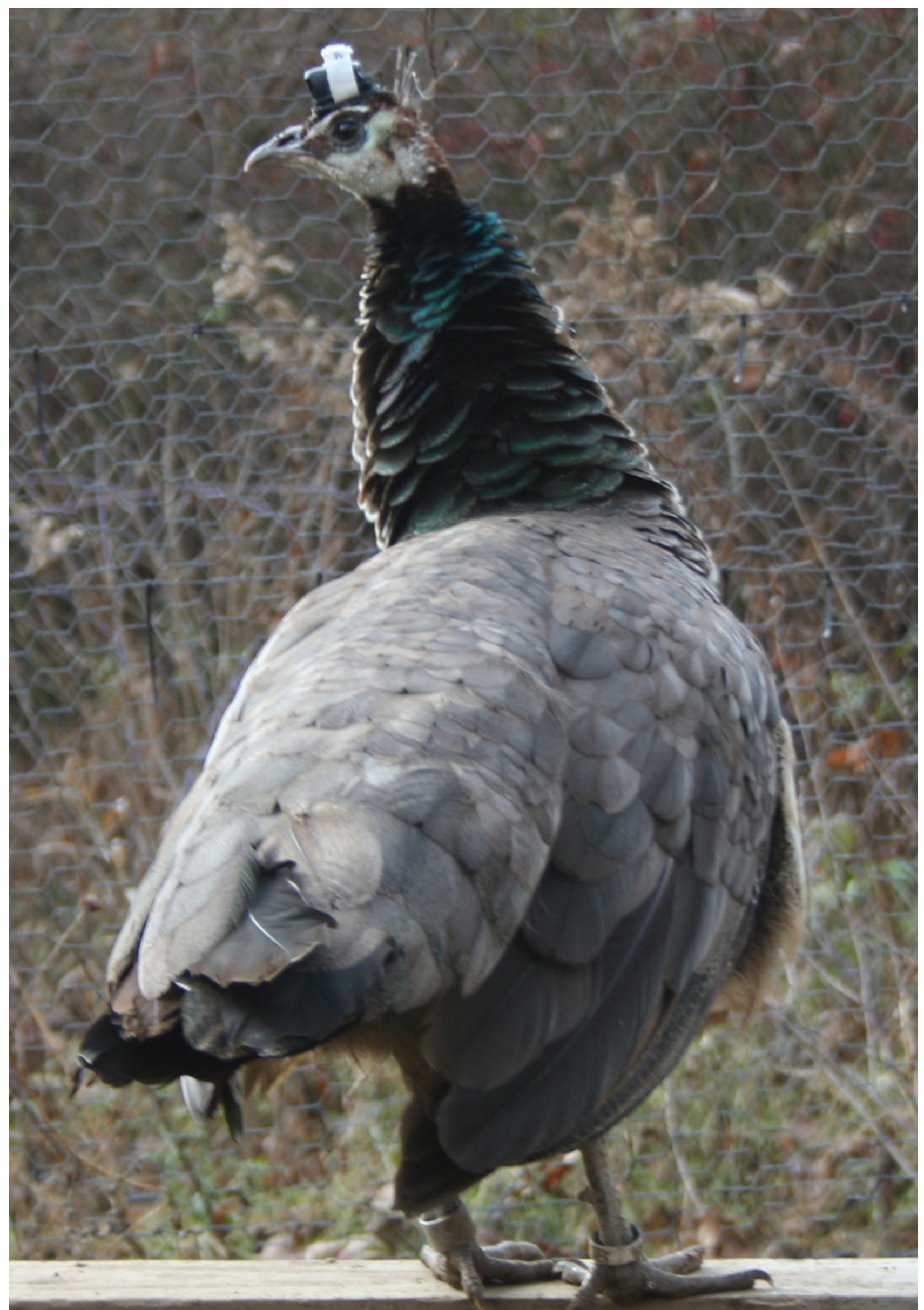


2

Figure 2
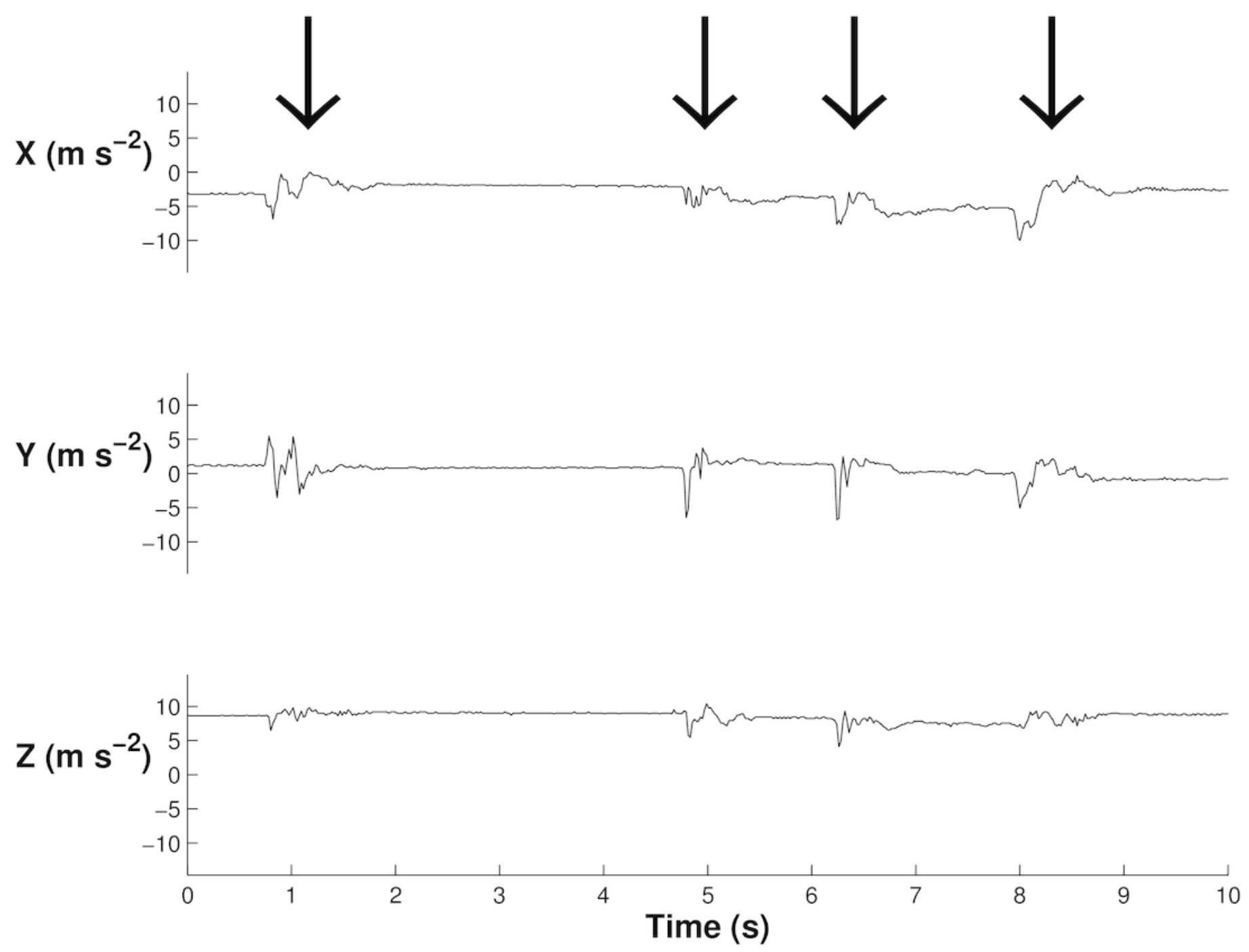
3

Figure 3

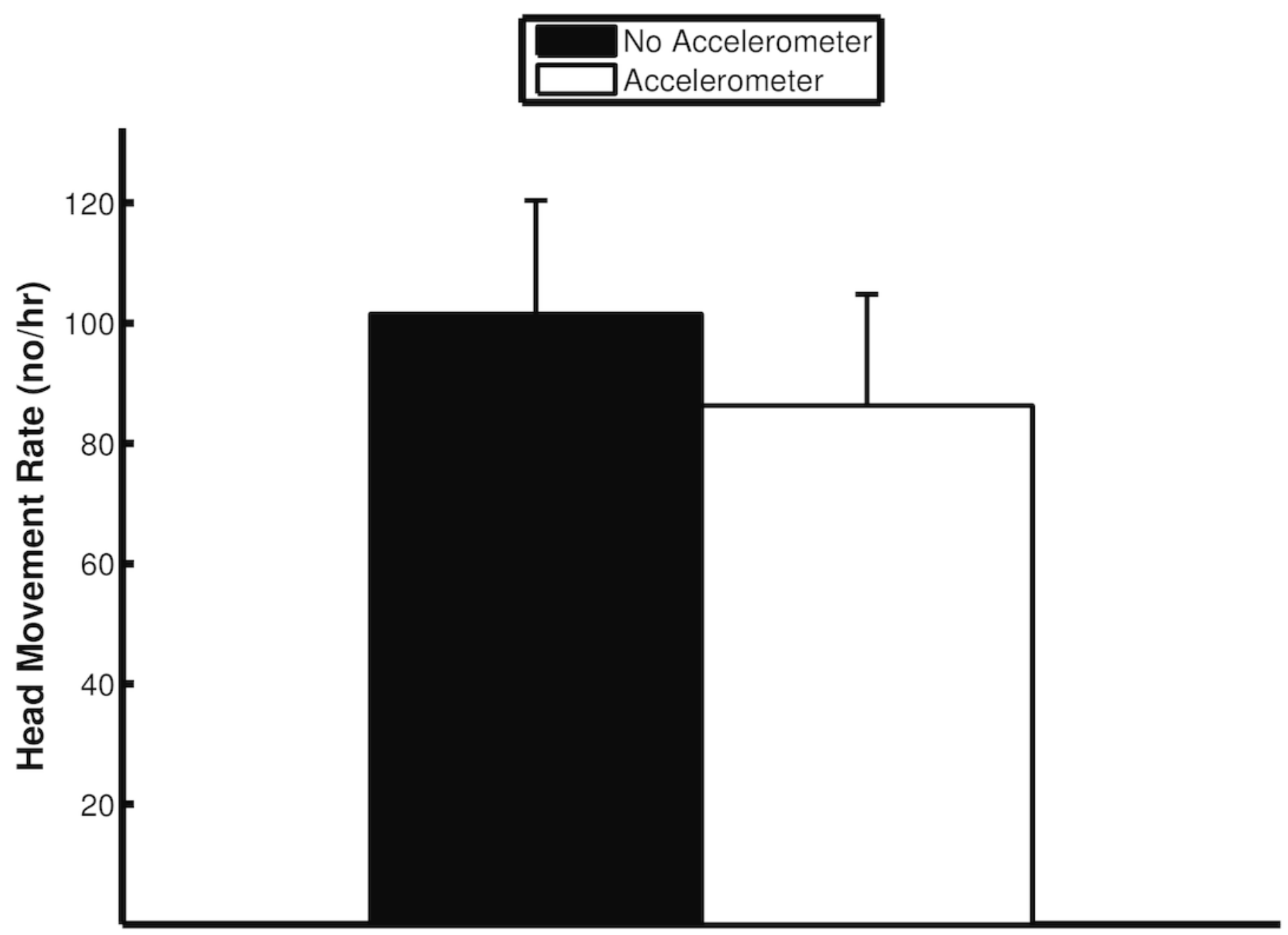


4

Figure 4

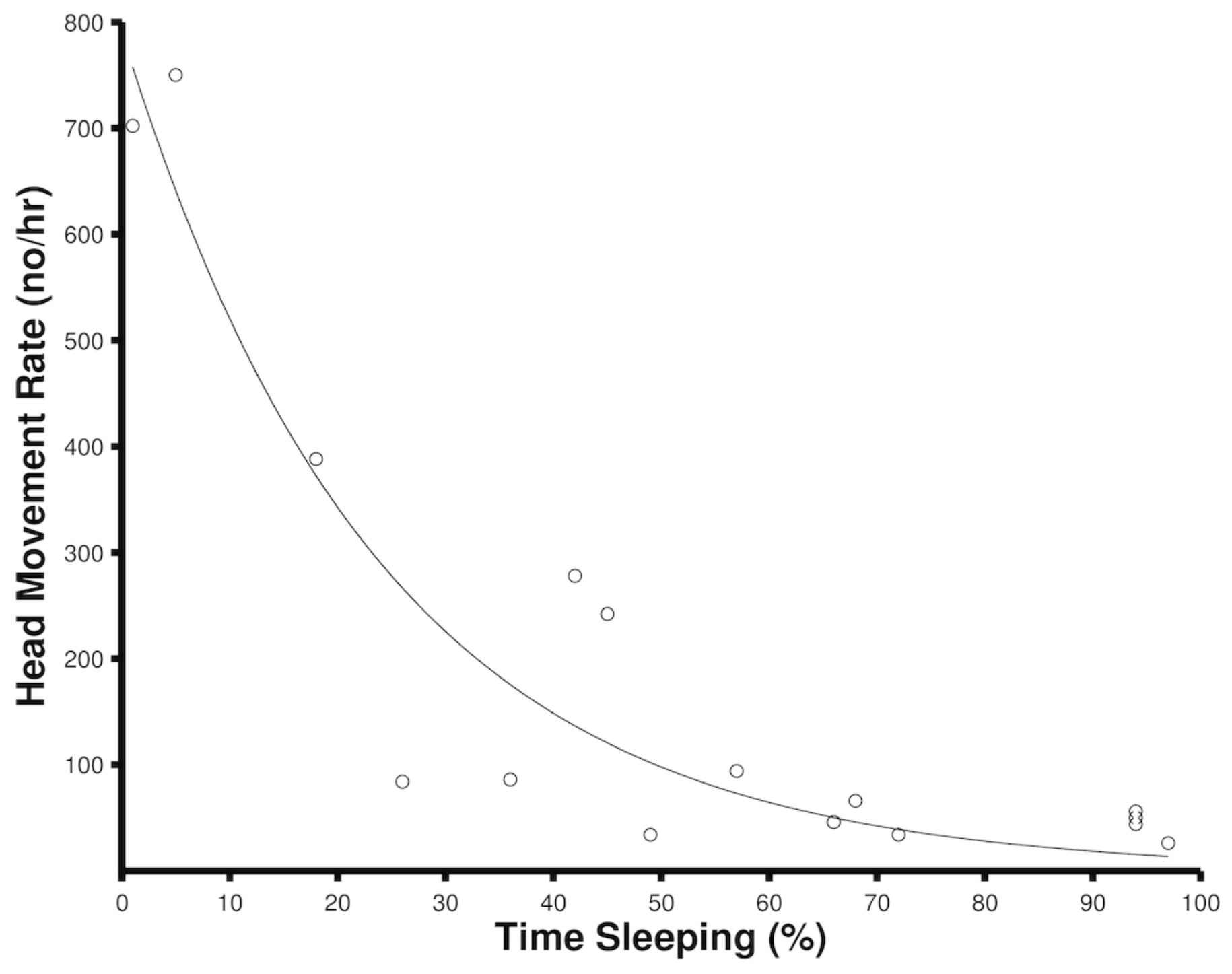


5

Figure 5

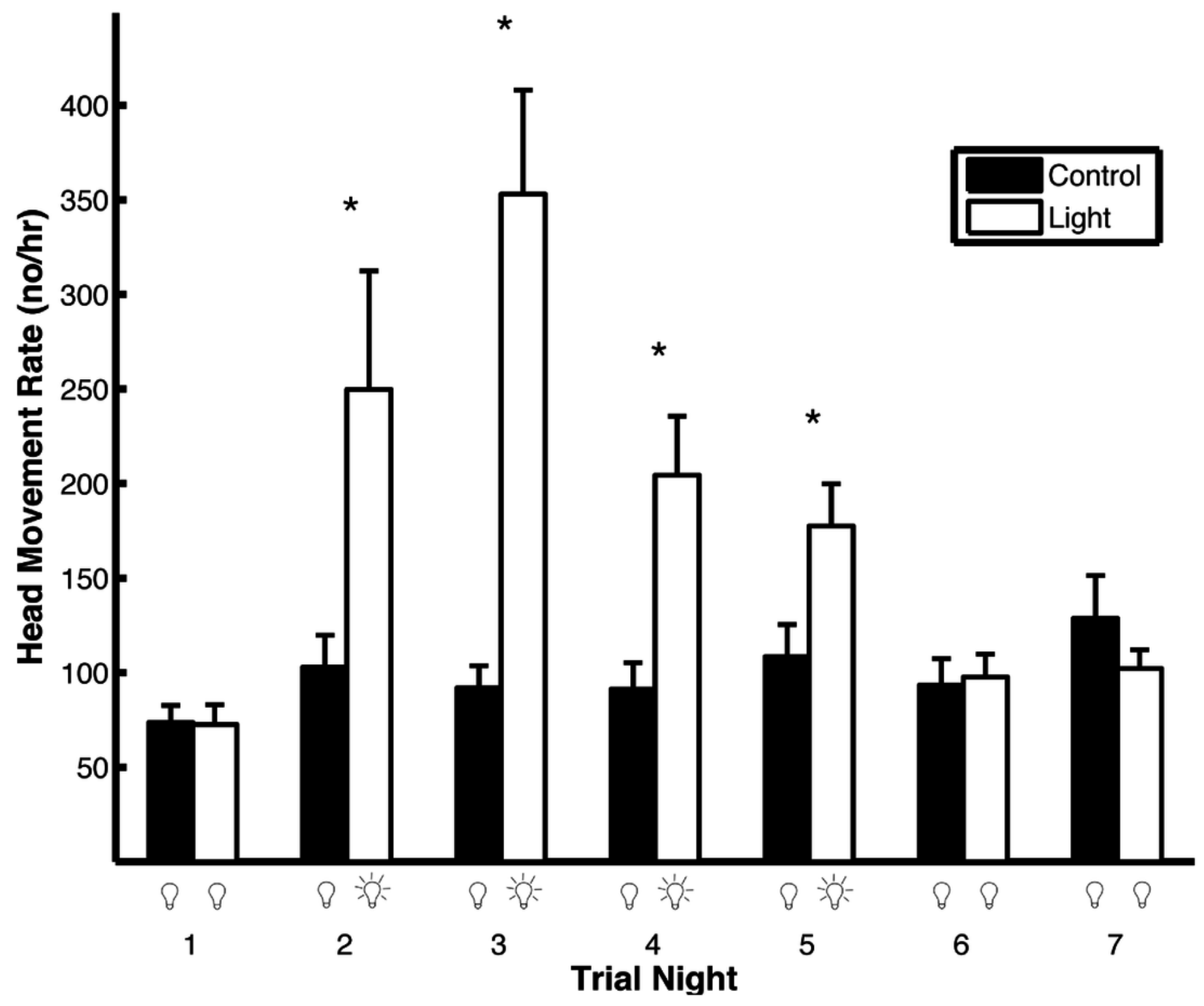

